\title{
Canadian recommendations for laboratory interpretation of multiple or extensive drug resistance in clinical isolates of
} Enterobacteriaceae, Acinetobacter species and Pseudomonas aeruginosa

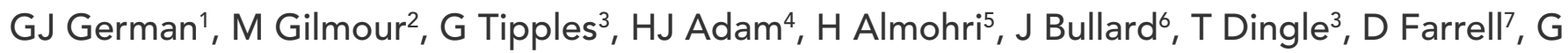 \\ Girouard $^{8}$, D Haldane ${ }^{9}$, L Hoang ${ }^{10}$, PN Levett ${ }^{7}$, R Melano ${ }^{11}$, J Minion ${ }^{12}$, R Needle ${ }^{13}$, SN Patel ${ }^{11}, \mathrm{R}$ \\ Rennie $^{3}$, RC Reyes ${ }^{14}$, J Longtin ${ }^{15}$, MR Mulvey ${ }^{2 \star}$
}

\begin{abstract}
The goal of this document was to provide Canadian laboratories with a framework for consistent reporting and monitoring of multidrug resistant organisms (MDRO) and extensively drug resistant organisms (XDRO) for common gram-negative pathogens. This is the final edition of the interim recommendations, which were modified after one year of broad consultative review. This edition represents a consensus of peer-reviewed information and was co-authored by the Canadian Public Health Laboratory Network and the Canadian Association of Clinical Microbiology and Infectious Diseases. There are two main recommendations. The first recommendation provides standardized definitions for MDRO and XDRO for gram-negative organisms in clinical specimens. These definitions were limited to antibiotics that are commonly tested clinically and, to reduce ambiguity, resistance (rather than non-susceptibility) was used to calculate drug resistance status. The second recommendation identifies the use of standardized laboratory reporting of organisms identified as MDRO or XDRO. Through the broad consultation, which included public health and infection prevention and control colleagues, these definitions are ready to be applied for policy development. Both authoring organizations intend to review these recommendations regularly as antibiotic resistance testing evolves in Canada.
\end{abstract}

\author{
Affiliations \\ ${ }^{1}$ Health PEI, Charlottetown, PEI \\ 2 National Microbiology Laboratory, \\ Winnipeg, MB \\ ${ }^{3}$ Alberta Provincial Laboratory for \\ Public Health, Edmonton, AB \\ ${ }^{4}$ Diagnostic Services Manitoba, \\ Winnipeg, MB \\ ${ }^{5}$ LifeLabs, Toronto, ON \\ ${ }^{6}$ Cadham Provincial Laboratory, \\ Winnipeg, MB \\ ${ }^{7}$ Saskatchewan Disease Control \\ Laboratory, Regina, SK \\ ${ }^{8}$ Centre hospitalier universitaire \\ Dr-Georges-L.-Dumont, Moncton, \\ NB \\ 9 Queen Elizabeth II Health Science \\ Centre, Halifax, NS \\ ${ }^{10}$ BC Centre for Disease Control \\ Public Health Laboratory, Vancouver, \\ BC \\ ${ }^{11}$ Public Health Ontario \\ Laboratories, Toronto, ON \\ ${ }^{12}$ Saskatchewan Health Authority, \\ Regina, SK \\ ${ }^{13}$ Newfoundland Public Health \\ Laboratory, St. John's, NL \\ ${ }^{14}$ LifeLabs, Burnaby, BC \\ ${ }^{15}$ Laboratoire de santé \\ publique du Québec, INSPQ, \\ Ste-Anne-de-Bellevue, QC
}

*Correspondence: michael. mulvey@canada.ca

\begin{abstract}
Suggested citation: German GJ, Gilmour M, Tipples G, Adam HJ, Almohri H, Bullard J, Dingle T, Farrell D Girouard G, Haldane D, Hoang L, Levett PN, Melano R, Minion J, Needle R, Patel SN, Rennie R, Reyes RC, Longtin J, Mulvey MR. Canadian recommendations for laboratory interpretation of multiple or extensive drug resistance in clinical isolates of Enterobacteriaceae, Acinetobacter species and Pseudomonas aeruginosa. Can Commun Dis Rep. 2018;44(1):29-34. https://doi.org/10.14745/ccdr.v44i01a07
\end{abstract}

\section{Introduction}

These recommendations were produced under the auspices and authority of the Canadian Public Health Laboratory Network (CPHLN) and the Canadian Association of Clinical Microbiology and Infectious Diseases (CACMID). They represent a consensus of peer-reviewed information and expert opinion on the most appropriate ways to define and report multidrug resistant phenotypes in common gram-negative pathogens. They build on previous interim recommendations (1) and underwent broad consultation with local, national, and international stakeholders. These recommendations are intended for use in Canadian non-veterinary clinical microbiology laboratories, and will enable standardized reporting in provincial and national surveillance programs. 


\section{Background}

Antimicrobial resistance is a growing concern for human health as bacterial pathogens continue to accumulate genetic alterations conferring resistance to the antimicrobials used to treat human infections. Most concerning is the acquisition of multiple resistance traits within individual pathogens, which can greatly limit or entirely eliminate the arsenal of effective treatment options, thereby leading to poor clinical outcomes. In Canada, we have observed these highly resistant strains in Enterobacteriaceae, Acinetobacter spp. and Pseudomonas aeruginosa (2-4).

The goal of this document is to provide Canadian laboratories with a framework for consistent reporting and monitoring of multidrug resistant organisms (MDRO) and extensively drug resistant organisms (XDRO). There was a need to standardize the classification of organisms that are resistant to multiple antimicrobials in order to consistently and accurately share information locally, nationally and internationally with the medical community, public health authorities and policy makers. Additionally, classification as 'multidrug resistant' may be an actionable finding within hospital infection prevention and control programs.

The need for standardized categorization of antimicrobial resistance was recognized in 2012 by Magiorakos et al. (5), who proposed interim international definitions in selected gram-positive and gram-negative organisms. Those definitions have not yet led to revised or definitive guidelines. The recommendations in this document are based on the interim definitions proposed by Magiorakos et al. for gram-negative organisms, with modifications to better reflect the Canadian context and take into account Canadian stakeholder input. See Appendix A for more information on the methodology for developing the final recommendations as well as a description of the modifications and their justifications. Table 1 identifies the broad provincial, national, and international consultations that were conducted with the interim recommendations.

Table 1: Provincial, national and international organizations consulted on the interim guidelines

\begin{tabular}{|c|c|}
\hline $\begin{array}{l}\text { Level of } \\
\text { consultation }\end{array}$ & Organization \\
\hline \multirow{8}{*}{ Provincial } & $\begin{array}{l}\text { British Columbia Association of Medical } \\
\text { Microbiologists (BCAMM) }\end{array}$ \\
\hline & $\begin{array}{l}\text { Diagnostic Services Manitoba Medical and Clinical } \\
\text { Microbiologists }\end{array}$ \\
\hline & $\begin{array}{l}\text { Provincial (Ontario) Infectious Diseases Advisory } \\
\text { Committee (PIDAC) }\end{array}$ \\
\hline & $\begin{array}{l}\text { GNB infection control committee of Comité sur les } \\
\text { infections nosocomiales du Québec (CINQ) }\end{array}$ \\
\hline & $\begin{array}{l}\text { Provincial (PEI) Infection Control and Prevention } \\
\text { Advisory Committee (PICPAC) }\end{array}$ \\
\hline & $\begin{array}{l}\text { Microbiologists, infection diseases physicians, and the } \\
\text { public health office (New Brunswick) }\end{array}$ \\
\hline & Microbiologists and Public Health Office (Nova Scotia) \\
\hline & $\begin{array}{l}\text { Microbiologists and Public Health Office } \\
\text { (Newfoundland) }\end{array}$ \\
\hline National & $\begin{array}{l}\text { Association of Medical Microbiology and Infectious } \\
\text { Disease (AMMI) Canada }\end{array}$ \\
\hline
\end{tabular}

Table 1: Provincial, national and international organizations consulted on the interim guidelines (continued)

\begin{tabular}{|c|c|}
\hline $\begin{array}{l}\text { Level of } \\
\text { consultation }\end{array}$ & Organization \\
\hline \multirow{5}{*}{ National (continued) } & Infection Prevention and Control Canada (IPCC) \\
\hline & Canadian College of Microbiologists (CCM) \\
\hline & $\begin{array}{l}\text { Public Health Networks Task Groups on AMR } \\
\text { Surveillance and AMR Infection Control }\end{array}$ \\
\hline & $\begin{array}{l}\text { Canadian Association of Clinical Microbiology and } \\
\text { Infectious Diseases (CACMID) }\end{array}$ \\
\hline & $\begin{array}{l}\text { Microbiology Scientific Committee of the Institute of } \\
\text { Quality Management in Health Care (IQMH) }\end{array}$ \\
\hline \multirow{3}{*}{ International } & Public Health England \\
\hline & Pan American Health Organization \\
\hline & $\begin{array}{l}\text { Transatlantic Taskforce on Antimicrobial Resistance } \\
\text { (TATFAR) }\end{array}$ \\
\hline
\end{tabular}

Abbreviation: GNB, gram-negative bacilli

Over time, as new antimicrobials become available and currently used antimicrobials lose effectiveness or are no longer available, these definitions will require revision. The recommendations stated herein are considered final and will be reviewed every three years.

\section{Recommendations for antimicrobial susceptibility testing}

1. A resistant interpretation of an isolate can be determined using disk diffusion, broth microdilution or agar dilution following Clinical and Laboratory Standards Institute (CLSI) guidelines for susceptibility testing and interpretation of Enterobacteriaceae, P. aeruginosa and Acinetobacter spp (6).

For data harmonization, emphasis is placed on minimum inhibitory concentration $(\mathrm{MIC})$ and phenotypic methods rather than expert rules providing interpretative criteria. A Health Canada- or Federal Drug Administration (FDA)- approved automated method or gradient diffusion strips can also be used for the generation of antimicrobial susceptibility data.

\section{Current CLSI M100 breakpoints should be used to determine} antimicrobial susceptibility of isolates (6).

Some laboratories may routinely use other breakpoint interpretations (e.g., FDA, European Committee on Antimicrobial Susceptibility Testing (EUCAST)) that differ from CLSI recommendations. Laboratories using non-CLSI breakpoints, including those using unmodified FDA-approved automated instruments, should disclose this information in their reports to provincial public health laboratories.

3. Certain species of Enterobacteriaceae should not be tested for particular antimicrobial agents because of intrinsic resistance.

Refer to the appendices of CLSI M100 (6) or EUCAST Expert Rules (7). 


\section{Definitions}

These recommendations are intended to be applied only to isolates from clinical/diagnostic specimens; however, infection prevention and control programs may choose to apply these MDRO/XDRO definitions in their antimicrobial resistant organism control activities. When reporting MDRO/XDRO isolates that are part of an asymptomatic surveillance program (e.g., inpatient admission screening), it should be clearly indicated in the laboratory report that the MDRO/XDRO classification refers to colonization or carriage status only in order to avoid unnecessary treatment.

In the following definitions, criteria using the term 'OR' should be interpreted as follows: if an isolate is resistant to either of the antimicrobial agents listed, it should be considered resistant to that criterion for the purposes of these definitions.

\section{Enterobacteriaceae definitions}

An isolate should be considered a MDRO if it is resistant to THREE OR FOUR of the SIX antimicrobial groups listed below:

- Tobramycin OR gentamicin (see exceptions for Serratia spp. in Table 2)

- Piperacillin-tazobactam

- Imipenem OR meropenem (see exceptions for Proteus spp. in Table 2)

- Cefotaxime OR ceftriaxone OR ceftazidime

- Ciprofloxacin

- Trimethoprim-sulfamethoxazole

An isolate should be considered an XDRO if it is resistant to FIVE OR SIX of the SIX antimicrobial groups listed above.

\section{Acinetobacter spp. or $P$. aeruginosa definitions}

There are no final recommendations for MDRO definitions for Acinetobacter spp. or $P$. aeruginosa. The previous interim recommendations for Acinetobacter spp. or $P$. aeruginosa MDRO status should be disregarded at this time (1).

An isolate should be considered an XDRO if it is resistant to ALL of the FIVE antimicrobial groups listed below:

- Ciprofloxacin

- Piperacillin-tazobactam (For P. aeruginosa can substitute piperacillin)

- Ceftazidime

- Imipenem OR meropenem

- Tobramycin

Table 2 provides a summary of the definitions for determining whether select gram-negative organisms are MDRO/XDRO.

\section{Reference laboratories notification}

The provincial public health laboratory should be notified of XDROs as defined above. Unlike the interim recommendations, sending of isolates is NOT requested. Referral of clinical isolates to reference laboratories should continue to occur as clinically
Table 2: Definitions for the determination of MDRO/XDRO in select organisms

\begin{tabular}{|c|c|c|c|}
\hline \multicolumn{2}{|c|}{ MDRO } & \multicolumn{2}{|r|}{ XDRO } \\
\hline Definition & $\begin{array}{l}\text { Antimicrobial } \\
\text { groups }\end{array}$ & Definition & Antimicrobial groups \\
\hline \multicolumn{4}{|c|}{ Enterobacteriaceae } \\
\hline \multirow{6}{*}{$\begin{array}{l}\text { Resistance } \\
\text { to THREE } \\
\text { OR FOUR } \\
\text { of the SIX } \\
\text { antimicrobial } \\
\text { groups }\end{array}$} & $\begin{array}{l}\text { Tobramycin OR } \\
\text { gentamicin }^{\mathrm{b}}\end{array}$ & \multirow{6}{*}{$\begin{array}{l}\text { Resistance } \\
\text { to FIVE OR } \\
\text { SIX of the } \\
\text { antimicrobial } \\
\text { groups }\end{array}$} & Tobramycin OR gentamicin \\
\hline & $\begin{array}{l}\text { Piperacillin- } \\
\text { tazobactam }\end{array}$ & & Piperacillin-tazobactam \\
\hline & $\begin{array}{l}\text { Imipenem OR } \\
\text { meropenem }^{c}\end{array}$ & & Imipenem OR meropenem \\
\hline & $\begin{array}{l}\text { Cefotaxime OR } \\
\text { ceftriaxone OR } \\
\text { ceftazidime }\end{array}$ & & $\begin{array}{l}\text { Cefotaxime OR ceftriaxone } \\
\text { OR ceftazidime }\end{array}$ \\
\hline & Ciprofloxacin & & Ciprofloxacin \\
\hline & $\begin{array}{l}\text { Trimethoprim- } \\
\text { sulfamethoxazole }\end{array}$ & & $\begin{array}{l}\text { Trimethoprim- } \\
\text { sulfamethoxazole }\end{array}$ \\
\hline \multicolumn{4}{|c|}{ Organisms: Pseudomonas aeruginosa OR Acinetobacter species } \\
\hline \multirow{5}{*}{$\begin{array}{l}\text { Not } \\
\text { applicable }\end{array}$} & \multirow[t]{5}{*}{ Not applicable } & \multirow{5}{*}{$\begin{array}{l}\text { Resistance } \\
\text { to ALL FIVE } \\
\text { antimicrobial } \\
\text { groups }\end{array}$} & Ciprofloxacin \\
\hline & & & Piperacillin-tazobactam ${ }^{d}$ \\
\hline & & & Ceftazidime \\
\hline & & & Imipenem OR meropenem \\
\hline & & & Tobramycin \\
\hline \multicolumn{4}{|c|}{$\begin{array}{l}\text { Abbreviations: MDRO, multidrug resistant organisms; XDRO, extensively drug resistant organism } \\
\text { a The term 'OR' should be interpreted as follows: if an isolate is resistant to either antimicrobial } \\
\text { agent listed, it should be considered resistant to that criterion for the purposes of these } \\
\text { definitions } \\
\text { b Resistance in Serratia spp. should only consider gentamicin susceptibility testing results } \\
\text { ' Resistance in Proteus spp. should only consider meropenem susceptibility testing results } \\
\text { d Resistance in P. aeruginosa may include piperacillin-tazobactam OR piperacillin. For all } \\
\text { Acinetobacter spp. piperacillin-tazobactam must be used }\end{array}$} \\
\hline
\end{tabular}

necessary. Provincial public health laboratories will collaborate on notification and particular privacy concerns in each province. Include the following information when reporting:

- Age of patient

- Gender of patient

- Type of clinical specimen (blood, respiratory, skin/soft tissue or urine)

- Date of collection

- Antimicrobial susceptibility testing results from submitting laboratory

- Method and interpretive criteria used for antimicrobial susceptibility testing, as described in the recommendations above

If multiple clinical isolates of the same species and susceptibility pattern are recovered from the same patient, report the isolate from the most invasive site where possible. Only one isolate of each XDRO should be reported per patient per year to the provincial laboratory.

The provincial public health laboratory as defined in Appendix B will report all of the data to the National Microbiology Laboratory (NML). The NML will compile and enable distribution of national surveillance reports to contributing laboratories and provincial public health authorities on an annual basis. 


\section{Conflict of Interest}

None.

\section{Acknowledgements}

We would like to acknowledge the work of Dr. John Conly (University of Alberta), Dr. Charles Frenette (McGill University), the Canadian Association of Clinical Microbiology and Infectious Diseases, and all the other members of the Canadian Infectious Disease Steering Committee Antimicrobial Resistance Surveillance Task Group. We also appreciate the support of Dr. George Zhanel (University of Manitoba) of the Canadian Antimicrobial Resistance Alliance and Dr. Anu Rebbapragada (Dynacare, Ontario) for feedback on earlier versions of the document. We thank members of the Canadian Public Health Laboratory Network Laboratory Director's Council for review and approval of the document. We would also like to thank Ms. Sandra Radons-Arneson and Ms. Alexis MacKeen for Secretariat support.

\section{Funding}

This work was supported in kind by all laboratories of the authors and the Canadian Public Health Laboratory Network Antimicrobial Resistance Subcommittee. The Secretariat support for this work was provided by the Public Health Agency of Canada.

\section{References}

1. German GJ, Jamieson FB, Gilmour M, Almohri H, Bullard $\mathrm{J}$, Domingo $\mathrm{MC}$ et al. Interim recommendations for the reporting of extensively drug resistant and pan-drug resistant isolates of Enterobacteriaceae, Pseudomonas aeruginosa, Acinetobacter spp. and Stenotrophomonas maltophilia. Can Commun Dis Rep. 2016;42(4):91-7. https://www.canada. $\mathrm{ca} / \mathrm{en} / \mathrm{public}$-health/services/reports-publications/canadacommunicable-disease-report-ccdr/monthly-issue/2016-42/ ccdr-volume-42-4-april-7-2016/ccdr-volume-42-4-april-72016-vaccine-preventable-diseases-3.html
2. Mataseje LF, Bryce E, Roscoe D, Boyd DA, Embree J, Gravel D et al. Canadian Nosocomial Infection Surveillance Program. Carbapenem-resistant Gram-negative bacilli in Canada 2009-10: results from the Canadian Nosocomial Infection Surveillance Program (CNISP). J Antimicrob Chemother 2012 Jun;67(6):1359-67. DOI (http://dx.doi. org/10.1093/jac/dks046).

3. Tien HC, Battad A, Bryce EA, Fuller J, Mulvey M, Bernard $\mathrm{K}$ et al. Multi-drug resistant Acinetobacter infections in critically injured Canadian forces soldiers. BMC Infect Dis 2007 Aug;7:95. DOl (http://dx.doi.org/10.1186/14712334-7-95). PubMed (https://www.ncbi.nlm.nih.gov/ entrez/query.fcgi?cmd=Retrieve\&db=PubMed\&list_ uids=17697345\&dopt=Abstract).

4. Laupland KB, Parkins MD, Church DL, Gregson DB, Louie TJ, Conly JM et al. Population-based epidemiological study of infections caused by carbapenem-resistant Pseudomonas aeruginosa in the Calgary Health Region: importance of metallo-beta-lactamase (MBL)-producing strains. J Infect Dis 2005 Nov;192(9):1606-12. DOI (http://dx.doi. org/10.1086/444469). PubMed (https://www.ncbi.nlm.nih. gov/entrez/query.fcgi?cmd=Retrieve\&db=PubMed\&lis t_uids=16206075\&dopt=Abstract).

5. Magiorakos AP, Srinivasan A, Carey RB, Carmeli Y, Falagas $\mathrm{ME}$, Giske CG et al. Multidrug-resistant, extensively drugresistant and pandrug-resistant bacteria: an international expert proposal for interim standard definitions for acquired resistance. Clin Microbiol Infect 2012 Mar;18(3):268-81. DOI (http://dx.doi.org/10.1111/j.14690691.2011.03570.x). PubMed (https://www.ncbi.nlm.nih. gov/entrez/query.fcgi?cmd=Retrieve\&db=PubMed\&lis t_uids=21793988\&dopt=Abstract).

6. Clinical and Laboratory Standards Institute (CLSI). PM100-S25 Performance Standards for Antimicrobial Susceptibility Testing; Twenty-Fifth Information Supplement. CLSI; Wayne (PA): 2015.

7. Leclercq R, Cantón R, Brown DF, Giske CG, Heisig P, MacGowan AP et al. EUCAST expert rules in antimicrobial susceptibility testing. Clin Microbiol Infect 2013 Feb;19(2):141-60. DOI (http://dx.doi.org/10.1111/j.14690691.2011.03703.x) PubMed (https://www.ncbi.nlm.nih. gov/entrez/query.fcgi?cmd=Retrieve\&db=PubMed\&lis t_uids=22117544\&dopt=Abstract). 


\section{Appendix A: Methodology for developing the final recommendations}

The article published by Magiorakos et al. (5) was used as the main reference for the development of these Canadian recommendations. Drs. German and Mulvey developed the initial framework for the document, which was reviewed by the Canadian Public Health Laboratory Network (CPHLN) Antimicrobial Resistance (AMR) Working Group members and invited collaborators. Two main considerations were discussed by the working group members: the formulation of a recommendation that focused on antimicrobial drugs commonly used in Canada; and the creation of a document that would be easy to use by frontline laboratories, which predominantly utilize automated methods for generating antimicrobial susceptibility data.

Three rounds of discussion and document revision took place with the working group. This included discussion and suggestions from the Communicable and Infectious Disease Steering Committee (CIDSC) AMR Task Group from the Pan-Canadian Public Health Network. The final draft recommendations were reviewed by the CPHLN Executive.

Major variation with recommendations in this document as compared to Magiorakos et al. (5) was as follows:

- The working group decided to focus on gram-negative isolates to keep the recommendations straightforward and achievable. It was decided that recommendations for gram-positive organisms would be addressed in a future document.

- The pan-drug resistant organisms (PDRO) nomenclature was eliminated in these revised recommendations as all potential antimicrobials are not tested routinely by clinical microbiology laboratories.

- Although the definition of MDRO in gram-negative organisms is an important consideration given the treatment complications that can be associated with these infections, it was decided at a provincial and national level to voluntarily report only XDRO isolates and use the identification of an MDRO as a screening test to direct further testing and reporting of resistant isolates.

- A great deal of discussion focused on the value of using the definition of resistance, as defined by CLSI, rather than that of non-susceptibility, as proposed by Magiorakos et al. (5). It was decided to use the CLSI definition of resistance based on the main arguments put forward, which were: front-line laboratories may have difficulty analyzing 'intermediate resistance' data in the context of MDRO/XDRO; and there were concerns about the reporting of these organisms in relation to public health. A stringent definition of resistance was determined to be the most feasible solution.

- It was noted that laboratories may have to use FDA breakpoints, which may differ from the CLSI breakpoints. It was requested in the recommendations that these differences be noted in the report to the local provincial public health laboratory.

- The exhaustive list of antimicrobial agents in the article by Magiorakos et al. (5) was simplified to reflect the antimicrobial agents commonly used and available in Canada.

- Ertapenem was removed as a marker for carbapenem resistance in Enterobacteriaceae. The specificity of ertapenem to detect acquired resistance is lower than that of meropenem and imipenem, and ertapenem-resistant isolates may be treated successfully by other carbapenems.

- The tetracyclines were removed from the list of antimicrobials to be considered as they are not frequently tested in frontline laboratories, nor are they commonly used to treat serious infections.

- The Canadian recommendations requested additional clinical information that was not included in the article by Magiorakos et al. (5).

- Nitrofurantoin and fosfomycin were removed from definitions as they do not represent currently accepted treatment options available for all infections, specifically invasive and more serious infections.

A broad provincial, national, international consultation process was conducted with the interim recommendations (Table 1). Feedback to the interim document led to the creation of several revisions. Since CACMID provided astute feedback of the interim document and would provide more front line clinical laboratory perspective they were invited to co-author the final recommendations. A task group was organized by CACMID. The recommendations were presented in near final form to the Annual 2017 CACMID general meeting. Further opportunities were provide for input from attendees. The final document was approved by the CACMID Board, the CPHLN AMR working group and the CPHLN Laboratory Council. 


\section{Appendix B: Reference laboratory contact information}

Dr. Linda Hoang, BCCDC Public Health Laboratories,

Vancouver, BC

linda.hoang@bccdc.ca

Dr. Tanis Dingle, Alberta Provincial Laboratory for Public Health, Edmonton, $A B$,

tanis.dingle@albertahealthservices.ca

Dr. Paul Levett, Saskatchewan Disease Control Laboratory,

Regina, SK

plevett@health.gov.sk.ca

Dr. Jared Bullard, Cadham Provincial Laboratory, Winnipeg, MB, jared.bullard@gov.mb.ca

Dr. Samir Patel, Public Health Ontario Laboratories, Toronto, ON samir.patel@oahpp.ca

Dr. Jean Longtin, Laboratoire de santé publique du Québec, Ste-Anne-de-Bellevue (OC)

jean.longtin@inspq.qc.ca
Dr. Gabriel Girouard, Centre hospitalier universitaire

Dr-Georges-L-Dumont,Moncton, NB

gabriel.girouard@vitalitenb.ca

Dr. David Haldane, Queen Elizabeth II Health Science Centre, Halifax, NS

david.haldane@cdha.nshealth.ca

Dr. Greg German, Queen Elizabeth Hospital, Charlottetown, PE gjerman@ihis.org

Robert Needle, Newfoundland Public Health Laboratory, St. John's, NL

robert.needle@easternhealth.ca

Dr. Michael Mulvey, National Microbiology Laboratory, Winnipeg, $\mathrm{MB}$

michael.mulvey@phac-aspc.gc.ca

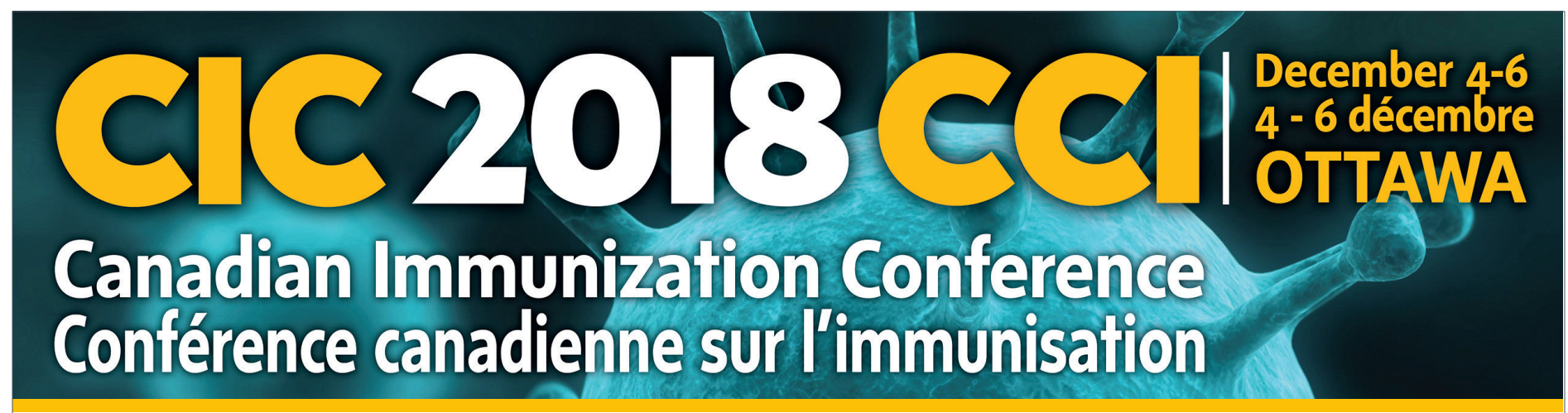

\section{WE WANT YOUR INPUT!}

The 2018 Canadian Immunization Conference will be the meeting place for the immunization community to connect, collaborate, innovate, inspire, share and learn.

Tell us about an emerging immunization issue or topic that you want to see profiled at CIC 2018 in any of the five learning streams established by the Conference Organizing Committee.

Complete the short survey here: http://form.simplesurvey.com/f/s.aspx? s=b56de4b9-43d l-4b 1 1-bda2-010b5a3c617a\&lang=EN 